\title{
Retraction Note: Analysis of DNA methylation polymorphism in a set of stable chromosome translocation lines
}

\author{
Shuangrong Li • Yong Zhang • Kejun Deng • \\ Jinhua Peng $\cdot$ Xuelian Zeng $\cdot$ Huaiqiong Zhang • \\ Zhenglong Ren
}

Published online: 1 November 2013

(C) Springer Science+Business Media Dordrecht 2013

Retraction to: Mol Breeding (2013) 32:165-176 DOI 10.1007/s11032-013-9860-x

This article, published in Molecular Breeding, volume 32, pages 165-176, doi:10.1007/s11032-013-9860-x, has been retracted at the request of the Editor-in-Chief because substantial parts were simultaneously submitted to and published in Chinese Science Bulletin, volume 53, pages 58-69, doi: 10.1007/s11434-0080049-3.

The online version of the original article can be found under doi:10.1007/s11032-013-9860-x.

S. Li · Y. Zhang $(\bowtie) \cdot$ K. Deng $\cdot$ J. Peng $\cdot$ X. Zeng School of Life Sciences and Technology, University of Electronic Science and Technology of China,

Chendu 610054, China

e-mail: zhangyong916@uestc.edu.cn

H. Zhang $\cdot$ Z. Ren ( $₫)$

State Key Laboratory of Plant Breeding and Genetics, Sichuan Agriculture University, Ya'an 625014, China e-mail: renzllab@sicau.edu.cn 